\title{
RESENHA DE LITERATURA EXPLICATIVA: ENSAIOS SOBRE RUY BELO
}

\author{
REVIEW LITERATURE EXPLANATORY: \\ ESSAYS ON RUY BELO
}

Aline Duque Erthal

Em texto sobre sua amizade com Ruy Belo - e sobre muito mais do que isso -, escreve João Miguel Fernandes Jorge: "Entrar na sua casa, abrir as janelas do seu olhar e ver através delas o mundo; e mais do que esse seu visualizado mundo, o mundo onde ficava, onde ficaria, onde fica, de facto, a sua casa”. Mirar por janela alheia evidentemente não transforma o visitante no dono da casa. Mas, se da mirada se fizer um exercício consciente de abertura, pode-se aprender novas formas de ler poesia, gente e mundo. Literatura Explicativa: ensaios sobre Ruy Belo, lançado em 2015 pela Assírio \& Alvim, traz 22 textos em que momentos verdadeiramente poéticos andam a ombros com investigações que prezam pelo rigor, e insights iluminam recenseamentos metódicos: os ensaístas colocam-se, francos, às janelas belianas; e ao fazê-lo - corrupção do tempo - reabrem para o contemporâneo os olhos de um dos maiores poetas da literatura em língua portuguesa, e que só recentemente começou a receber um pouco da atenção que lhe é devida pela academia e pelo mercado editorial brasileiros.

O livro, organizado por Manaíra Aires Athayde, divide-se em seis partes temáticas: "Lugares, paisagens e intertextualidade"; "Torrencialidade, fragmentos e montagem"; "Amor, mulher: traços de memória e despedida"; "O tradutor, o ensaísta"; "Esquecimentos e desencontros"; e, por fim, "Deus e a morte e a arte". Ficam evidentes, conforme se avança na leitura, as conexões multidirecionais que transbordam de uma parte para a outra, indicando-nos uma das características belianas que leva o próprio 
sujeito lírico a se denominar, em determinada altura, um "poeta líquido". Marítima é a obra de Ruy Belo, no fundo e na forma, nos motivos e no ritmo, como bem mostra Ida Alves logo no primeiro ensaio do livro ( $\mathrm{Li}$ teratura explicativa é então, poderíamos dizer, uma obra-paisagem dessa outra obra-paisagem que é a poesia beliana). Leitora da fenomenologia hermenêutica de Paul Ricoeur e Merleau-Ponty e pesquisadora dos estudos contemporâneos sobre a teoria do lirismo, para os quais Michel Collot é referência fundamental, Ida demonstra que o mar é a paisagem-pensamento que "sustenta, organiza e movimenta as direções" do imaginário beliano, tanto no nível da subjetividade individual como no coletivo, histórico - e, sobretudo, no da linguagem poética em si mesma.

Convidar outras vozes à página é atitude sempre produtiva para se pensar um poeta (no caso em questão, dir-se-ia quase indispensável: Ruy Belo sempre se assumiu um cruzamento de olhares - "A maior acusação que um poeta pode dirigir a um antecessor é a de o não ter influenciado. Ler alguém e não lhe ficar a dever nada é a maior decepção possível para quem tem na poesia a sua razão de vida”, escreveu a certa altura). No seu percurso reflexivo, Ida ilumina diálogos com Álvaro de Campos; e, já no ensaio seguinte, Cristina Firmino Santos convoca António Nobre e Raul Brandão para suas investigações acerca das metáforas marítimas na obra de Belo. Resultado: ela e leitor acompanham um sujeito errante no salgado incomensurável, em risco e aventura, mas aventura desde sempre, nessa poesia, elegíaca, dolorosamente sensível à passagem do tempo: sem retorno, aventura de adeus.

Como onda que arrasta sargaços, detritos das que lhe precederam, esmigalhando uns (Pessanha), acrescentando outros, a poesia de Ruy Belo carrega restos, em práticas citacionais que são esmiuçadas por Paula Morão. Atenta às referências (explícitas ou não) a outras obras e investigando manuscritos com emendas feitas pelo poeta, a ensaísta revela novas camadas do bi(multi)linguismo dessa escrita.

Poeta que não encontra habitação em tempo ou lugar algum, apenas no outro constituído do múltiplo ("Sem alteridade não há unidade", diz-nos um de seus versos), Ruy Belo inspira o texto heterodoxo e irônico de Jorge Fernandes da Silveira, que declara com acerto: "o lugar do poeta Ruy Belo é cada dia mais no Brasil" (impossível não lembrar, aqui, o quão bem-vinda é a coleção lançada em 2013 pela 7Letras, editando em nossas terras os nove livros lançados em vida pelo poeta. A coleção é coordenada por Manoel Ricardo de Lima, ele mesmo um dos ensaístas a colaborar com Literatura explicativa). Jorge parte da fala do homem afogado para empreender uma singular navegação por mares já dantes navegados: os de Camões, de Pessoa, de Sena, afinal um só oceano, uma mesma aventura a que também nós, leitores, somos tragados. Ramificam-se os cruzamentos, os fios desse lençol de água.

No descobrimento a que somos convidados, alguns mergulhos em 
close reading fazem saltar aos olhos aspectos estruturantes de determinados poemas. Gastão Cruz é um dos que expõem as vigas dessa arquitetura: com ênfase sobre os poemas longos, evidencia com bem pinçados exemplos a oscilação entre "uma construção milimétrica, por vezes quase clássica" e "um discurso mais críptico, não raro torrencial e revolto". Dessa forma, o crítico e também poeta assinala - como já o fizera em outras oportunidades - a associação entre uma "teoria do rigor" e o "poder restituído à palavra", feita por muita da poesia na passagem da década de 1950 para a de 1960, para defender que a produção poética do século XX transita entre dois polos: rigor e liberdade. $\mathrm{Ou}$, em outras palavras: construção e desconstrução.

Os poemas longos belianos espraiam-se para o texto seguinte, de Rosa Maria Martelo. A ensaísta vem se dedicando há algum tempo à discussão do papel da alegoria na poesia moderna portuguesa, apoiando-se em Walter Benjamin (que resgatara o conceito da desvalorização de que fora alvo a partir do Romantismo). Em Literatura explicativa, as lentes recaem sobre os procedimentos de alegoria, fragmento e montagem na obra beliana, lida à luz de Álvaro de Campos. Rosa argumenta que ambos contrapõem a alegoria ao símbolo. A diferença entre os dois conceitos seria uma questão de experiência do tempo - "A alegoria inscreve distância em relação à sua própria origem e, renunciando à nostalgia e ao desejo de coincidência, estabelece a sua linguagem no vazio dessa diferença temporal". Ao mostrar o quanto a forma dos poemas longos é coerente com esse modo de percepção alegorista - do que permanece inacessível, à distância, omisso -, Rosa passa a refletir sobre os procedimentos cinematográficos nos versos, outro de seus domínios de discussão, e mostra a relação entre a atitude poética alegorista e os gestos de montagens textuais, confisco ou recoleta de imagens.

Se Rosa vai ao cinema para ler Ruy Belo, Vasco Graça Moura, sem ignorá-lo, escuta também música, observa a arquitetura e, sobretudo, tateia com os olhos esculturas (mais especificamente, os túmulos de Pedro e Inês entalhados em pedra) para percorrer fragmentos do poema "A margem da alegria", que ocupa todo um livro e retoma a história de amor e morte de D. Pedro I e Inês de Castro. Salientando a exigência prosódica de seus 2161 versos, Graça Moura encaminha-nos pela "deriva ecfrástica" entre tempo individual e eternidade, entre "a plenitude almejada e a própria impossibilidade dela", em atravessamento de tempos históricos e subjetivos, "entre vários espaços do mundo e da alma" - para, por fim, alertar-nos para o quanto de ironia tem esse texto e o quanto o amor é, uma vez mais na poesia, potência subversiva.

É esse preciso ponto do ensaio de Graça Moura que vai, aos ouvidos do leitor, ressoar no texto de Fernando Pinto do Amaral, dedicado a refletir sobre o funcionamento e a função do amor na escrita beliana. É quando se percebe um certo mecanismo de fixação proporcionado pelo sentimento: o amor permite a subsistência, ou que uma imagem venha "a confluir para o reino da eternidade”. Assim, memória e imaginação propi- 
ciam um transporte amoroso no tempo, e as figuras femininas, alvo do sentimento do sujeito lírico, integram uma hipótese de absoluto, na medida em que são capazes de induzir contraditoriamente "a antecipação da perda e a vertigem da eternidade".

De amor e de morte se faz a poesia de Ruy Belo, sua ética e sua estética. Luis Maffei, em texto que em si mesmo é - como, aliás, de bom hábito desse professor, poeta e pesquisador - aventura de linguagem, risco enfrentado com amor, confessa o quanto o poeta português está no entre de suas leituras de poesia, de suas escritas de poesia (e, agora atesto-o eu, também de suas aulas de poesia). Ruy Belo, e Luis com ele, põe a escrita poética a serviço de um ideal de comunhão humana, sem jamais prescindir de algo que constitui, afinal, condição para qualquer palavra que se queira poética: a transgressão. Mas, afinal, "como pode a poesia ser sábia e comungante se é complicada e violadora?"; "A que tipo de bem, ou de justiça, a poesia pode levar?", pergunta Luis. Ao propor essas questões, o ensaísta ressalta e repete o convite - na verdade, a exigência - que Ruy Belo faz ao leitor: acolhamos paradoxos, sejamos fiéis ao compromisso com a linguagem acima de tudo, no projeto (e não, prescrição) de tornar possível a poesia. Em "labor parceiro", comunguemos na complicação, no desvio.

Transgridamos, portanto. Assim o fazem ensaístas deste livro e assim o faz Ruy Belo - como poeta e também como tradutor. Nuno Júdice, lendo versos de outros escritores vertidos para o português por Belo, revela o esforço para que nada se perca do que é dito na língua estrangeira - o que é dito e, sobretudo, o como dizer. Observa-se, assim, que no ofício da tradução Belo ora assume uma invisibilidade, tornando o outro texto seu próprio texto, ora intervém vocabular ou gramaticalmente, tanto no aspecto formal quanto no semântico, "para que não se ouça o estranho da outra língua na expressão corrente da nossa”. Com esses desvios que acrescentam novas ressonâncias aos versos, conclui Júdice, liberta-se o poeta tradutor "dessa 'literalidade' que pode matar o poético".

Violência, desvio? Disto se trata a poesia. Clara Rowland passa pela reflexão sobre a catacrese como abuso e sobre a violência corretiva que marca essa escrita para demonstrar como, nos versos belianos, pode-se trocar "coisa por coisa" (a mesma palavra pode significar coisas diferentes, e palavras diferentes podem encetar uma relação de equivalência), em efeito arduamente conquistado no labor poético. E, se ao significante a poesia dirige sua atenção máxima, ao mesmo cuidado se vê obrigado o trabalho do crítico. Manoel Ricardo de Lima, por exemplo, em determinada altura de seu texto, com justeza observa ser Ruy Belo "um poeta da vida moderna em prospecção e defasagem anacrônicas", a trabalhar com desregulação regrada da metamorfose - e salienta: metamorfose como a forma por dentro (meta), e não mera transformação, passagem de uma forma a outra. Todo o ensaio reserva outras (des)apropriações de linguagem, recriando novidades - saindo ele mesmo do formato "estrutura estruturada" para se fazer enquanto "estrutura estruturante" - em gesto muitas vezes poético, como 
que a atender a uma demanda da própria escrita beliana: a de se deixar embalar pela palavra líquida e flutuar em funções infixas.

Já Marcos Aparecido Lopes mais uma vez assume o risco de ler um tema polêmico e até mesmo, algumas vezes, evitado quando se trata de Ruy Belo: o lugar de deus e a tradição religiosa em sua poesia. O ensaísta argumenta que ambos jamais se evadem da obra beliana; eles continuam, depois de Aquele Grande Rio Eufrates (escrito ainda sob influência da Opus Dei, prelazia à qual o poeta pertenceu durante 10 anos) e até o último livro, como questão posta e pulsante - o que, como Lopes costuma frisar e com perspicácia, nada tem a ver com pura aderência ao corpo doutrinário do cristianismo. $\mathrm{O}$ assunto ocupa a atenção do ensaísta há tempos, e, no artigo publicado em Literatura explicativa, Lopes faz notar algo que talvez seja uma conexão entre a relação de Ruy Belo com Deus e a relação do poeta com a letra: esta é a encarnação de uma esperança de redenção (de vencer o tempo, de permanecer) e ao mesmo tempo atestado de óbito, marca de morte, inscrição em lápide.

Também sobre a questão de deus, Manaíra Athayde percorre caminhos distintos, e faz algo ainda raro: uma incursão pelo espólio de Ruy Belo, trazendo à luz emendas feitas pelo poeta em Aquele Grande Rio Eufrates, em que palavras relacionadas ao universo religioso, como "deus" e "senhor", foram substituídas por outras, relacionadas às ideias do artista e de seu olhar, como o "grande criador". As referidas emendas foram feitas logo após a publicação do quarto título do poeta, Homem de Palavra[s], e a ensaísta vai se dedicar a mostrar o quanto o livro foi um divisor de águas no percurso beliano.

Esta resenha visitou alguns portos, mas deixou outros por tratar. Incontáveis seriam as rotas de interesse possíveis - basta listar os nomes dos demais ensaístas, bastante conhecidos por qualquer leitor de poesia e crítica portuguesa: Eduardo Lourenço, Emílio Rui Vilar, Golgona Anghel, Gustavo Rubim, J. B. Martinho, Jorge Valentim, Luís Mourão, Pedro Serra. O fim do volume ainda guarda uma útil fortuna crítica, listando outros livros, teses, dissertações, artigos, ensaios, resenhas e críticas publicadas a respeito do poeta. Leiamos, então, Literatura explicativa, investidos da atenção sensível que Ruy Belo e esses ensaístas nos incitam a ter.

Recebido para publicação em 13/09/2015 Aprovado em 15/02/2016

\section{NOTAS}

* Doutoranda em Literatura Portuguesa na Universidade Federal Fluminense (UFF), com bolsa da Capes. Possui mestrado em Literatura Portuguesa pela mesma universidade; especialização em Literaturas e Culturas de Língua Portuguesa: Portugal e África, também pela UFF; e graduação em Comunicação Social/Jornalismo pela Universidade do Estado do Rio de Janeiro. 